\title{
ATROFIA MUSCULAR PROGRESSIVA
}

\section{Estudo clínico e laboratorial em onze pacientes}

\author{
Maria Elisabeth Matta de Rezende Ferraz', Edmar Zanoteli, \\ Acary Souza Bulle Oliveira ${ }^{3}$, Alberto Alain Gabbai4
}

\begin{abstract}
RESUMO - A atrofia muscular progressiva (AMP) é um tipo raro de doença do neurônio motor (DNM) com acometimento exclusivo do neurônio motor inferior (NMI) e com características clínicas bem definidas. A eletroneuromiografia é o principal exame subsidiário para a realização do diagnóstico, com demonstração de alterações neurogênicas generalizadas, agudas e crônicas. Outras doenças que mimetizam comprometimento do NMI devem ser excluídas através de investigação laboratorial ampla. Neste estudo são apresentados 11 casos de AMP (5,9\% de todos os nossos casos de DNM), sendo 9 homens e 2 mulheres. 0 início dos sintomas ocorreu preferencialmente abaixo dos 50 anos, com média de idade de 45,5 anos. A cãibra foi o sintoma que mais comumente precedeu a fraqueza muscular. Outras queixas preliminares foram dor, fadiga muscular e fasciculações. O padrão mais freqüente de inauguração dos sintomas foi fraqueza muscular assimétrica, preferencialmente nos membros superiores. Com a evolução da doença, todos os pacientes apresentaram comprometimento bulbar. Não foi identificado nenhum fator predisponente para a doença, nem tampouco as evoluções foram distintas entre os casos. Oftalmoparesia e acometimento dos esfíncteres, sinais pouco comuns nas DNMs, foram observados em dois pacientes que se mantiveram por longo tempo em respiração artificial. As terapêuticas imunossupressoras / imunomodulatórias utilizadas (ciclofosfamida, gamaglobulina hiperimune, plasmaferese) não tiveram resultado favorável. A doença teve caráter progressivo em todos os casos. Todos os pacientes faleceram, com tempo médio de sobrevida de 44 meses.
\end{abstract}

PALAVRAS-CHAVE: atrofia muscular progressiva, esclerose lateral amiotrófica, doenças do neurônio motor, doenças neuromusculares.

\begin{abstract}
Progressive muscular atrophy: clinical and laboratory study in eleven patients
ABSTRACT - Progressive muscular atrophy (PMA), an infrequent type of motor neuron disease (MND), is a predominantly lower motor neuron degeneration, causing muscle wasting and weakness with loss of weight and fasciculations. The diagnosis is based on rigid criteria, considering clinical aspects and eletroneuromyography findings. Blood tests and radiological investigation are necessary to look for other diagnosis mimicking PMA. We herein present 11 patients with PMA (5.9\% of all our MND patients), 9 men and 2 women, which onset of symptoms occurred mainly under de age of 50, with a mean of 45.5 years. Cramp was the most frequent symptom preceding muscular weakness. Muscle pain, fatigue and fasciculations were also cited as starting symptoms. Asymmetric weakness of the arms was the most frequent pattern of onset of the disease. Bulbar muscular weakness developed in all patients during the course of the disease. Predisposing factors and distinctive clinical outcome was not observed in any of the patients. Ophthalmoparesis and esfincter dysfunction were seen in two patients who had a prolonged time in artificial respiratory assistance. Imunnossupressive therapy was ineffective in all patients. Progressive course was seen in all cases and the mean survival time was 44 months.
\end{abstract}

KEY WORDS: progressive muscular atrophy, amyotrophic lateral sclerosis, motor neuron disease, neuromuscular disease.

Neuronopatia motora compreende grupo de doenças em que há comprometimento do corpo celular do neurônio motor superior (NMS) e/ou inferior (NMI). Dentre essas doenças destaca-se o grupo denominado de doenças do neurônio motor (DNM), de natureza degenerativa, evolutiva e irreversível, apresentando-se sob quatro formas clínicas específicas: esclerose lateral primária (ELP) caracte-

Setor de Doenças Neuromusculares (DNM), Disciplina de Neurologia, Universidade Federal de São Paulo, Escola Paulista de Medicina (UNIFESP-EPM), São Paulo SP, Brasil: ' ${ }^{1}$ Mestre em Neurologia, ${ }^{2}$ Doutor em Medicina, ${ }^{3}$ Chefe do Setor de DNM, ${ }^{4}$ Professor Titular, chefe da Disciplina de Neurologia.

Recebido 28 Maio 2003, recebido na forma final 8 Agosto 2003. Aceito 19 Setembro 2003. 
rizada por acometimento puro do NMS; atrofia muscular progressiva (AMP) caracterizada pelo envolvimento isolado do NMI; esclerose lateral amiotrófica (ELA) em que há sinais combinados de lesão de NMS e NMI; paralisia bulbar progressiva (PBP) em que ocorre acometimento isolado ou predominante dos neurônios motores bulbares. Há um certo consenso de que a PBP está inserida no contexto da ELA ${ }^{1,2}$. Em relação à AMP, há autores que a consideram também como estágio inicial da $E^{2}{ }^{2}$ e há aqueles que a consideram entidade isolada ${ }^{3-7}$. Há estudos anatomopatológicos que comprovam a existência de casos de acometimento isolado do $\mathrm{NMI}^{8}$.

A AMP, considerada a forma de apresentação mais rara das DNMs, é pouco estudada como entidade isolada. Dentre as justificativas destacam-se: dificuldade diagnóstica e ausência de um marcador diagnóstico específico; dificuldade de distinção, baseando-se em critérios eletrofisiológicos, entre a AMP e a neuropatia puramente axonal ${ }^{9}$ e confusão de nomenclatura com a amiotrofia espinhal progressiva (AEP). Diferentemente da AMP, a AEP é doença hereditária, com herança autossômica recessiva, de início, em geral, na infância, caracterizada por degeneração das células do corno anterior da medula espinhal e associada com mutações no gene $S M N(5 q)^{10}$. O quadro clínico, a faixa etária de acometimento e o prognóstico são quase sempre suficientes para diferenciar a AMP da AEP ${ }^{10}$. No entanto, naqueles casos de AEP de início na vida adulta (AEP tipo IV) a diferenciação é mais difícil.

O objetivo deste estudo é apresentar o quadro clínico e laboratorial de um grupo de doentes com os critérios diagnósticos de AMP, bem como a resposta destes pacientes à imunossupressão/imunomodulação, com a respectiva evolução clínica.

\section{MÉTODO}

São apresentados 11 pacientes com diagnóstico de AMP, com idade variando de 31 a 70 anos (média 45,5 anos e mediana de 44 anos), selecionados dentre um grupo de 186 doentes com o diagnóstico de DNM de início na vida adulta. Para o diagnóstico de AMP foram utilizados critérios bem estabelecidos ${ }^{6,11}$, baseando-se na presença de todos os critérios de inclusão e de nenhum critério de exclusão:

A) Critérios de inclusão - 1. Quadro clínico de caráter progressivo caracterizado por acometimento isolado do neurônio motor inferior (sem envolvimento clínico do neurônio motor superior em qualquer fase da doença). 2. Todas as formas de sensibilidade preservadas. 3 . Ausência de sinais clínicos ou laboratoriais sugestivos de outra doença de base. 4. Eletroneuromiografia (ENMG) com velocidade de condução normal, ausência de bloqueio de condução multifocal e potenciais sensitivos normais. Eletromiografia de agulha com achados compatíveis com desnervação difusa, aguda e crônica. 5. Início dos sintomas após 16 anos de idade.

B) Critérios de exclusão - 1. História familiar de polineuropatia. 2. História de irradiação prévia na coluna. 3. Pacientes com acometimento de NMI confinado a um membro apenas, ou que se mantiveram com quadro de paraparesia braquial ou crural sem progressão para os outros membros. 4. Evidência sorológica ou clínica de doenças do tecido conectivo (lupus eritematoso sistêmico, periarterite nodosa, sarcoidose, doença de Behçet, síndrome de Sjogren). 5. Manifestações no sistema nervoso central por sífilis, doença de Lyme, HIV, HTLV-1, hepatite $B$ ou C, enteroviroses. 6. Líquido cefalorraquiano (LCR) com alterações inflamatórias. 7. Ressonância magnética (RM) de coluna cervical com comprometimento medular.

Todos os pacientes foram avaliados pela autora (MEMRF) em pelo menos uma oportunidade. Para avaliação da força muscular foi utilizado o MMT ("Manual Muscle Testing") $)^{12}$

Todos os pacientes foram submetidos a exames de ENMG dos 4 membros e da língua, RM da coluna cervical e da transição crânio-cervical e de LCR por punção lombar.

Com o intuito de excluirmos outras doenças, foram realizados os seguintes exames: hemograma, velocidade de hemosedimentação, glicemia de jejum, transaminases, TSH e T4 livre, dosagem da enzima creatinoquinase (CK), imunoglobulinas séricas e eletroforese de proteínas sérica (EFP), dosagem das imunoglobulinas IgA, IgG e IgM, avaliação reumatológica (fator anti-nuclear, pesquisa de células $L E$, complemento sérico, proteína $C$-reativa), reações sorológicas (lues, HIV, HTLV-1, hepatite B e C, citomegalovírus, mononucleose), dosagem de alguns metais pesados (mercúrio e chumbo), radiografia (RX) de tórax, ultrassonografia (US) abdominal e pélvica e mielograma. Dosagem de anticorpos anti-GM1 e asialo-GM1, realizada pelo Laboratório Scripps (San Diego, Califórnia, EUA) foi obtida nos pacientes 4 e 6 . Biopsia de músculo foi realizada nos pacientes 3, 4, 6 e 11 . Apenas o paciente 4 foi submetido a biopsia de nervo sural.

\section{RESULTADOS}

A) Aspectos epidemiológicos - A idade de início dos sintomas variou de 31 a 70 anos (média 45,5 anos). Em 8 casos $(72,7 \%)$ a doença teve início antes da quinta década. Sete pacientes $(63,6 \%)$ eram da raça branca e quatro $(36,4 \%)$ eram da raça negra. Nenhum paciente era proveniente de zona rural ou tinha história prévia ou exame compatíveis com seqüela de poliomielite. Não houve qualquer 
relato de contato com agrotóxicos, metais pesados ou com substâncias químicas. 0 paciente 7 sofreu queda de 5 metros de altura com fratura de uma costela, alguns meses antes do início dos sintomas. No caso 10 havia história de trauma crânio-encefálico com perda de consciência, dois anos antes do início da doença. Em relação aos antecedentes familiares, os pacientes 8 e 9 eram irmãos, não havia consangüinidade entre os pais e nem tampouco outros casos de DNM nessa família. Não havia história familiar de outra doença neurodegenerativa, como doença de Parkinson ou doença de Alzheimer. Nenhum paciente ou familiar tinham história de disfunção tireoidiana (Tabela 1).

B) Aspectos clínicos - Em 8 casos $(72,7 \%)$ houve algum sintoma precedendo a manifestação de fraqueza muscular: em 6 pacientes ocorreram cãibras, principalmente noturnas e nas panturrilhas; em um caso houve dor no membro que, posteriormente, ficaria fraco e em um outro houve queixa de fadigabilidade no membro que, depois, ficou fraco. A instalação da fraqueza foi considerada o início da doença. Em todos os pacientes o quadro teve início com fraqueza muscular em um ou mais membros. Nenhum paciente apresentou manifestações bulbares iniciando o quadro. A inauguração dos sintomas foi simétrica em 7 casos $(63,6 \%)$ e assimétrica no restante deles (Tabela 2). Os achados do exame neurológico da primeira consulta estão resumidos na Tabela 3. Os itens de exame neurológico não citados nas tabelas estavam normais.
C) Exames subsidiários - A dosagem da CK foi normal em sete pacientes e aumentada (até 5 vezes o limite superior da normalidade) em cinco casos. Dosagens dos anticorpos anti-GM1, anti-MAG e anti-sulfatídeo, não apresentaram anormalidade. O exame do LCR mostrou elevação da taxa de proteínas em três casos. A RM de coluna cervical e transição crânio cervical foi normal em 6 casos. Nos outros casos havia alterações compatíveis com espondilodiscoartropatia, mas sem qualquer comprometimento medular (Tabela 4).

A análise histológica do tecido muscular dos pacientes submetidos a biopsia muscular revelou atrofia neurogênica crônica inespecífica, caracterizada pela presença de fibras atróficas anguladas e por agrupamento de fibras do mesmo tipo histoquímico. A biopsia de nervo sural realizada no paciente 4 mostrou número normal de fibras mielinizadas, sem alterações compatíveis com degeneração axonal. Não havia "brotamentos" ou sinais de inflamação. O exame com imunofluorescência no nervo para detecção de depósito de $\lg \mathrm{A}, \lg \mathrm{G}$, IgM, fração 3 do complemento e NGFrec ("Nerve Growth Factor receptor") não mostrou anormalidades.

D) Tratamento - Todos os pacientes foram tratados com drogas imunossupressoras (azatioprina, ciclofosfamida) e/ou com procedimentos imunomodulatórios (plasmaférese ou imunoglobulina hiperimune). Os pacientes 1 e 8 receberam prednisona na dose de $60 \mathrm{mg} /$ dia por seis e cinco meses respectivamente, previamente. Ciclofosfamida oral, na

Tabela 1. Dados demográficos, idade (em anos) do ínicio dos sintomas e da primeira consulta e duração da doença (em meses) até o óbito em 11 pacientes com AMP.

\begin{tabular}{cccccc}
\hline Paciente & $\begin{array}{c}\text { Sexo/ } \\
\text { Cor }\end{array}$ & Profissão & AP & $\begin{array}{c}\text { Início/1a } \\
\text { consulta }\end{array}$ & $\begin{array}{c}\text { Duração da } \\
\text { doença }\end{array}$ \\
\hline 1 & F/B & Dolar & NS & $33,5 / 35$ & 18 \\
2 & M/N & Sapateiro & Prostatismo & $70 / 72$ & 38 \\
3 & M/B & Industrial & Hipertensão arterial & $47 / 48$ & 41 \\
4 & M/B & Contador & NS & $31 / 33$ & 60 \\
5 & M/N & Empreiteiro & Hipertensão arterial & $44 / 47$ & 58 \\
6 & M/N & Pedreiro & Etilismo & $63,5 / 65$ & 31 \\
7 & M/N & Montador & Etilismo, fratura de costela & $61 / 62$ & 26 \\
8 & F/B & Do lar & Pan-histerectomia & $38,5 / 40$ & 52 \\
9 & M/B & Motorista & NS & $34 / 34$ & 36 \\
10 & M/B & Policial & Diarréia crônica, TCE & $33 / 33$ & 45 \\
11 & M/B & Administrador & Halterofilismo & $44 / 50$ & 82 \\
\hline
\end{tabular}

NS, nada significativo; $M$, masculino; $F$, feminino; $A P$, antecedentes pessoais; $N$, negro; $B$, branco; TCE, traumatismo crânio encefálico. 
Tabela 2. Manifestações Iniciais.

\begin{tabular}{|c|c|c|c|c|c|c|c|c|}
\hline \multicolumn{5}{|c|}{ Sintomas que precederam a fraqueza muscular } & \multicolumn{4}{|c|}{ Distribuição da fraqueza muscular no início da doença } \\
\hline Caso & Cãibra & Fasc. & Dor & Fadiga & $\begin{array}{c}\text { MMSS } \\
\text { Simétrica }\end{array}$ & $\begin{array}{c}\text { MMSS } \\
\text { Assimétrica }\end{array}$ & $\begin{array}{c}\text { MMII } \\
\text { Simétrica }\end{array}$ & $\begin{array}{c}\text { MMII } \\
\text { Assimétrica }\end{array}$ \\
\hline 1 & MMII & - & - & - & Distal & - & - & - \\
\hline 2 & - & - & - & - & + & - & - & - \\
\hline 3 & - & - & - & - & Distal & - & - & - \\
\hline 4 & MMII & - & - & - & - & - & Distal & - \\
\hline 5 & MMII & - & - & - & - & $E>D$ & - & - \\
\hline 6 & Gen. & + & - & - & - & - & + & - \\
\hline 7 & - & - & MSE & - & - & $E>D$ & - & - \\
\hline 8 & MMII & - & - & - & - & - & - & MID \\
\hline 9 & Gen & Gen & - & - & - & - & - & MID \\
\hline 10 & - & - & - & + & + & - & + & - \\
\hline 11 & - & - & - & - & + & - & - & - \\
\hline
\end{tabular}

+, presente; -, ausente; MMII, membros inferiores; MSE, membro superior esquerdo; Gen., generalizado; E, esquerdo; D, direito; >, maior; MID, membro inferior direito; MMSS, membros superiores; Fasc., fasciculação.

Tabela 3. Achados do exame fisico na primeira consulta: força muscular (MMT*), atrofia muscular, fasciculações, reflexos tendíneos e acometomento bulbar**.

\begin{tabular}{|c|c|c|c|c|c|c|c|c|}
\hline Caso & Fasciculações & Atrofia muscular & Reflexos tendíneos & $\begin{array}{l}\text { Acometimento } \\
\text { bulbar }\end{array}$ & $\begin{array}{l}{ }^{*} \mathrm{MS} \\
\text { Prox }\end{array}$ & $\begin{array}{l}{ }^{*} \mathrm{MS} \\
\text { Dist }\end{array}$ & $\begin{array}{l}{ }^{*} \mathrm{MI} \\
\text { Prox }\end{array}$ & $\begin{array}{l}{ }^{*} \mathrm{MI} \\
\text { Dist }\end{array}$ \\
\hline 1 & $\mathrm{M} / \mathrm{T}$ & MS/prox e dist & Abolidos globalmente & Não & 2 & 2 & 4 & 4 \\
\hline 2 & $\mathrm{M} / \mathrm{T}$ & MS/prox e dist & Abolidos globalmente & Não & 4 & 4 & 3 & 3 \\
\hline 3 & M & MS/dist & Abolidos globalmente & Não & 2 & 1 & 4 & 0 \\
\hline 4 & $M$ & MS/dist e MI/prox & Abolidos globalmente & Não & 5 & 4 & 4 & 4 \\
\hline 5 & $\mathrm{~T}$ & MS/dist & $\begin{array}{c}\text { Abolidos MS } \\
\text { Normais nos MI }\end{array}$ & Não & 4 & 3 & 5 & 5 \\
\hline 6 & $\mathrm{M} / \mathrm{T}$ & - & Abolidos globalmente & Não & 4 & 5 & 2 & 3 \\
\hline 7 & $M / T / L$ & $\begin{array}{c}\text { MS/prox e dist e } \\
\text { MI/prox }\end{array}$ & Hipoativos globalmente & Sim & 4 & 3 & 5 & 4 \\
\hline 8 & $\mathrm{M} / \mathrm{T} / \mathrm{L}$ & $\begin{array}{l}\text { MS e Ml/ } \\
\text { prox e dist }\end{array}$ & Abolidos globalmente & Sim & 2 & 1 & 1 & 0 \\
\hline 9 & $\mathrm{M} / \mathrm{T}$ & - & $\begin{array}{c}\text { Normais nos MS } \\
\text { Abolidos MI }\end{array}$ & Sim & 5 & 5 & 5 & 3 \\
\hline 10 & $\mathrm{M} / \mathrm{T} / \mathrm{L}$ & MS/prox e dist & Abolidos globalmente & Sim & 4 & 3 & 4 & 3 \\
\hline 11 & $\mathrm{M} / \mathrm{T} / \mathrm{L}$ & $\begin{array}{l}\text { MS e MI/ } \\
\text { prox e dist }\end{array}$ & Abolidos globalmente & Sim & 3 & 3 & 3 & 3 \\
\hline
\end{tabular}

M, membros; T, tórax; L, língua; +, presente; -, ausente; MI, membros inferiores; MS, membros superiores; prox, proximal; dist, distal. * O MMT quantifica o grau de força muscular em um determinado músculo. Os resultados acima mostram a média dos achados nos grupos de músculos (proximal ou distal). ** Nos casos 7, 8, 10 e 11 havia fasciculação de língua e no caso 9 havia fala rouca. 
Tabela 4. Avaliação com exames subsidiários.

\begin{tabular}{|c|c|c|c|c|c|}
\hline Caso & RM cervical & RM torácica & RM lombar & $\mathrm{CK}^{*}$ & $\begin{array}{c}\text { Proteínas totais } \\
\text { do LCR (normal } \\
\text { até } 40 \mathrm{mg} / \mathrm{dl} \text { ) }\end{array}$ \\
\hline 1 & Discopatia C5-C6 & NR & NR & $1.5 \times$ & $\mathrm{NI}$ \\
\hline 2 & Discopatia C3-C4 e C4-C5 & NR & NR & $\mathrm{NI}$ & $\mathrm{NI}$ \\
\hline 3 & Abaulamento $\mathrm{C} 5-\mathrm{C} 6$ e $\mathrm{C} 6-\mathrm{C} 7$ & $\mathrm{NI}$ & $\mathrm{NI}$ & $\mathrm{NI}$ & 71 \\
\hline 4 & $\mathrm{NI}$ & $\mathrm{NI}$ & $\begin{array}{l}\text { Espinha bífida } \\
\text { oculta L5 e sacral }\end{array}$ & $\mathrm{NI}$ & $\mathrm{NI}$ \\
\hline 5 & $\begin{array}{l}\text { Protrusão discal C4-C5 e C5-C6 } \\
\text { c/ compressão lateral medular }\end{array}$ & NR & NR & $\mathrm{NI}$ & $\mathrm{NI}$ \\
\hline 6 & Artrose & NR & Artrose & $5 x$ & 56 \\
\hline 7 & $\mathrm{NI}$ & NR & NR & $\mathrm{NI}$ & 67 \\
\hline 8 & $\mathrm{NI}$ & $\mathrm{NI}$ & NR & $\mathrm{NI}$ & $\mathrm{NI}$ \\
\hline 9 & $\mathrm{NI}$ & NR & NR & $2 x$ & $\mathrm{NI}$ \\
\hline 10 & $\mathrm{NI}$ & $\mathrm{NI}$ & NR & $1,2 \times$ & $\mathrm{NI}$ \\
\hline 11 & $\mathrm{NI}$ & NR & NR & $1,1 \times$ & $\mathrm{NI}$ \\
\hline
\end{tabular}

$\mathrm{RM}$, ressonância magnética; $\mathrm{NI}$, normal; $\mathrm{NR}$, não realizado; $\mathrm{CK}$, creatinoquinase; $\mathrm{LCR}$, líquido cefalorraqueano. *CK, vezes o limite superior da normalidade.

dose de 2 a $3 \mathrm{mg} / \mathrm{Kg} / \mathrm{dia}$, foi administrada a todos os pacientes, em alguma fase da doença, por períodos de duração variáveis. Em muitos deles, foi necessário suspender o seu uso devido a efeitos secundários (hematúria, leucopenia, intolerância gástrica, cólicas intestinais). Azatioprina oral, na dose de 2 $\mathrm{mg} / \mathrm{kg} / \mathrm{dia}$, foi administrada a dois pacientes. Imunoglobulina hiperimune endovenosa (Sandoglobulina $\left.\AA^{\circledR}\right)$, na dose de $400 \mathrm{mg} / \mathrm{kg} / \mathrm{dia}$, por 5 dias e por três meses consecutivos, e plasmaférese com troca de $40 \mathrm{ml} / \mathrm{Kg} / \mathrm{sessão} / 5$ sessões foram administradas aos pacientes 3 e 4 . Não foi observado nenhum indício de melhora ou de estabilização clínica com o uso destas formas terapêuticas em qualquer dos pacientes.

E) Evolução clínica - Todos os pacientes evoluíram com piora progressiva da doença, com fraqueza dos quatro membros, além de acometimento da musculatura bulbar (disfonia, disfagia e fasciculação e atrofia na língua). Fraqueza da musculatura cervical com impossibilidade de sustentação do segmento cefálico foi observada em 7 pacientes (pacientes $1,3,4,5,8,10$ e 11). Todos os doentes tornaram-se dependentes quanto às atividades da vida diária, em média cerca de 27,2 meses após a instalação dos primeiros sintomas. Foi considerada incapacidade a perda de marcha sem apoio ou necessidade de cadeira de rodas, ou a paresia num grau tal que tornou o doente dependente em suas atividades da vida diária, ou disfonia num grau que o doente não podia mais ser compreendido, ou disfagia em que se fez necessária a utilização de sonda naso-enteral, ou dispnéia que impedia o paciente de realizar alguma atividade.

Os pacientes 3 e 4 foram mantidos em respirador artificial por longo período, respectivamente de 2 anos e 10 meses e 1 ano e 11 meses. Quando faleceu, o doente 3 estava tetraplégico e com plegia da movimentação ocular extrínseca bilateralmente, com comprometimento associado da função esfincteriana (retenção fecal e urinária). Na época do falecimento, o paciente 4 também estava tetraplégico e com paresia do sexto nervo bilateralmente, mas sem comprometimento esfincteriano. Nenhum paciente apresentou durante a evolução sinais de liberação piramidal.

Todos os 11 pacientes faleceram em decorrência de pneumonia e insuficiência respiratória, com exceção do paciente 3. Este paciente, embora tetraplégico e restrito ao leito por longo período, não apresentou infecção do trato respiratório e a causa do óbito não foi identificada. O tempo médio de evolução da doença, desde o início das manifestações até o falecimento, foi 44 meses.

\section{DISCUSSÃO}

Em amostra de 186 pacientes com o diagnóstico de DNM/ELA, de início tardio, 11 (5,9\%) preencheram os critérios para AMP, porcentagem próxima 
a encontrada em outros estudos ${ }^{13}$. Houve predominância do sexo masculino ( 4,5 homens / mulher), fato semelhante ao de outros estudos ${ }^{2,4,7}$. A maioria dos casos $(72,7 \%)$ teve início dos sintomas antes dos 50 anos, com média de idade de 45,5 anos, dados próximos aos encontrados por Mortara et al. ${ }^{5}$, que observaram idade média de 46 anos na época do início da doença, e Gunnarsson et al. ${ }^{3}$, com idade de início, na maioria dos casos, inferior a 50 anos. Neste estudo grande parte dos doentes $(45,5 \%)$ inaugurou o quadro de AMP entre os 30 e os 40 anos de idade. Em estudo epidemiológico brasileiro a idade de início da forma ELA foi ao redor de 50 $\operatorname{anos}^{14}$.

Os fatores de risco considerados como predisponentes para AMP como exposição à agrotóxico, solventes, mercúrio e chumbo, trabalho rural e choque elétrico ${ }^{3,15,16}$, não foram identificados em nenhum dos nossos casos. Atividade física freqüente e a prática de esportes têm sido associadas à DNM, sendo relatada em $36 \%$ dos pacientes com DNM contra $12 \%$ da população em geral ${ }^{17}$. Somente dois dos nossos pacientes, um halterofilista e outro pedreiro, desenvolveram atividade física extenuante. Apesar de termos notado dois casos com história prévia de trauma, não tem sido comprovada na literatura uma ligação entre história prévia de trauma físico e desenvolvimento de $\mathrm{DNM}^{3,15}$. Embora citada com freqüência como fator de risco para $\mathrm{DNM}^{17}$, história prévia de infecção pelo poliovírus não foi identificada em nenhum de nossos doentes. A maior incidência de tireoideopatia entre os acometidos de DNM e em seus familiares ${ }^{18}$ não foi observada em nossa amostra refletindo talvez, uma associação casual entre estas duas doenças, ou, ainda, que elas possam ter uma base imunológica como fator etiopatogênico. Não observamos também descrição de doenças neurológicas degenerativas, tais como doença de Parkinson e demências, nos familiares dos nossos pacientes, dado diferente dos relatados por Deapen et al. ${ }^{15}$ e Gunnarsson et al. ${ }^{3}$.

Os pacientes 8 e 9 eram irmãos, indicando um caráter familiar. Neles o início dos sintomas ocorreu abaixo dos 40 anos, idade abaixo da média encontrada para os nossos casos. Esta tendência ao início mais precoce da forma familiar da doença já foi demonstrada ${ }^{6,19}$. Em torno de 5 a $10 \%$ dos casos de ELA são familiares, e nestes em torno de $20 \%$ são causados por mutações no gene da superoxido dismutase (SOD1), cuja herança é, na maioria dos casos, autossômica dominante ${ }^{19}$. Embora não tenha- mos realizado análise da gene $S M N$ nestes dois irmãos para excluir a AEP, a evolução desfavorável não é compatível com tal diagnóstico, mesmo naqueles raros casos de início na vida adulta. Também estes pacientes não foram avaliados quanto a alteração do gene SOD1. Moulard et al. ${ }^{20}$ encontraram, em um grupo de 14 pacientes com diagnóstico de AMP dois casos com deleção no gene SMNt (configurando o diagnóstico de AEP de início tardio) e $36 \%$ com deleção do gene $S M N c$, uma porcentagem muito acima daquela observada na população normal (até $5 \%$ ). Nos casos de ELA (177 pacientes) e ELP (66 pacientes) os autores encontraram deleção do gene $S M N c$ em apenas $6,2 \%$ e $1,5 \%$ respectivamente, uma percentagem próxima ao esperado, comparando-se com a população normal. Os casos de ELA e ELP com deleção do gene SMNc não apresentaram diferenças estatísticas comparando-se com os casos sem deleção considerando a época do início, a sobrevida média, e o sexo. Em contrapartida, os casos de AMP com deleção do gene $S M N c$ apresentaram início mais precoce da doença e quadro clínico mais grave com relação aos casos de AMP sem a deleção sugerindo que, de alguma forma, a ausência do gene SMNc interfira na patogênese da doença, ou mesmo funcionaria como um fator de predisposição genética ${ }^{20}$.

Sintomas aparentemente inespecíficos, tais como fasciculação, dor, fadiga ${ }^{1,2,21}$ e, principalmente, cãibra ${ }^{1}$ têm sido freqüentemente relatados antes do aparecimento da paresia, fato semelhante encontrado nesta amostra, sugerindo uma atividade excessiva do motoneurônio, previamente. Em todos os nossos casos o sintoma inaugural da doença foi fraqueza muscular nos membros, predominando nos membros superiores, como descrito por ou$\operatorname{tros}^{1,4,22}$. Dos nossos quatro pacientes que tiveram o início da fraqueza nos membros inferiores, três eram muito jovens e três deles faleceram após tempo relativamente menor de doença. Comprometimento bulbar inicial, relatado em algumas séries em até $20 \%$ dos pacientes ${ }^{1,22}$, não foi identificado em nenhum dos nossos casos. A fraqueza teve início simetricamente em 7 casos e de maneira assimétrica em 4 casos. $O$ acometimento clínico assimétrico é o mais freqüentemente relatado ${ }^{22}$, concorde com estudos anatomopatológicos que mostraram achados assimétricos de lesão na medula espinhal, principalmente no início do quadro ${ }^{8}$. A relativa assimetria inicial dos sinais e sintomas se dilui na evolução do quadro ${ }^{21}$, fato também constatado no nosso estudo. 
Os exames subsidiários têm como finalidade a confirmação do diagnóstico de AMP e a exclusão de eventuais doenças sistêmicas relacionadas ${ }^{23,24}$. A ENMG é fundamental para o diagnóstico e para a distinção de algumas situações, tais como o bloqueio de condução multifocal ${ }^{9,24}$. A análise dos anticorpos anti-GM1, anti-MAG e anti-sulfatídeo também tem auxiliado nesta diferenciação ${ }^{23}$. $\mathrm{O}$ exame de $L C R$, com taxas de proteína acima de $0,75 \mathrm{~g} / \mathrm{L}^{25}$, tem-se mostrado útil para o diagnóstico de associação da DNM com linfoma. Três dos nossos pacientes apresentaram taxa aumentada de proteína, no LCR, mas não excedendo $0,75 \mathrm{~g} / \mathrm{l}$. Um comprometimento associado da coluna cervical ou lombar poderia justificar o aumento de proteína, no LCR na maioria dos casos com dissociação proteíno-citológica. Guildff et al. ${ }^{26}$ não encontraram diferenças clínicas ou na evolução de doença entre os pacientes que apresentaram proteínas normais ou alteradas. Para os autores, poderia haver um transudato sérico devido à lesão da barreira hematoencefálica e esta pode ser a causa de pequenas alterações na taxa protéica do LCR. A avaliação de imagem com RM pelo menos da coluna cervical e da transição crânio-cervical é necessária para a exclusão de mal formações, tumores ou alterações ósseo-degenerativas locais ${ }^{21,24}$. Em nossos casos encontramos apenas alterações compatíveis com discoartropatias degenerativas da coluna, sem sinais de compressão medular. Dosagem aumentada da CK, descrita em 45 a $50 \%$ dos casos de DNM ${ }^{13}$, mostrouse presente em 5 dos nossos doentes. Este aumento enzimático, mais freqüentemente visto na forma de DNM com envolvimento puro do $\mathrm{NMI}^{21}$, às vezes muito acima do valor normal, pode trazer uma confusão diagnóstica com as miopatias, mas não reflete, necessariamente, um pior prognóstico ${ }^{13}$. Os achados de biopsia de músculo refletem o processo de desenervação, como era esperado ${ }^{13}$. A importância da biopsia muscular reside na necessidade de distinção clínica com as miopatias distais, muitas vezes com quadro clínico e evolução indistinguíveis da AMP. A biopsia de nervo sural só teria indicação para excluir aqueles casos suspeitos de envolvimento de nervo periférico, com comprometimento motor puro.

Independentemente do esquema terapêutico utilizado e do tempo de uso da droga, em nenhum caso houve melhora ou estabilização da doença. Outros estudos também demonstram ineficácia medicamentosa, com evolução clínica com piora progressiva ${ }^{27,28}$. Todos os doentes apresentaram padrão evolutivo similar, com tetraparesia, hipotrofia muscular e acometimento bulbar. Nos pacientes 3 e 4 houve manutenção prolongada dos doentes em respirador artificial. Um grupo especial de doentes em que se deve sempre considerar o uso de ventilação auxiliar ou artificial é aquele em que os pacientes apresentam insuficiência respiratória precoce, sem ou com pouca fraqueza muscular dos membros, ou sem comprometimento bulbar ${ }^{29}$. A insuficiência respiratória precoce pode ocorrer por fraqueza exacerbada da musculatura respiratória ou por paralisia do diafragma secundária à própria doença. Nesta última, há um comprometimento precoce das células da coluna ventromedial do cordão anterior da medula de C3 a C5, onde estão os núcleos frênicos ${ }^{29}$. Nos pacientes 3 e 4 foi possível observar oftalmoparesia durante a evolução clínica. $\mathrm{Na}$ literatura pesquisada não foram encontrados estudos anatomopatológicos de pacientes com AMP e oftalmoparesia. Há porém, várias descrições de ELA com oftalmoparesia que ao estudo anatomopatológico demonstrou-se degeneração dos núcleos oculomotores e até lesões supra-nucleares ${ }^{30}$. Estudos anatomopatológicos mostram que os núcleos de Onuf, que estão localizados a nível sacral e inervam os esfíncteres estriados urinário e anal estão comprometidos, mesmo que não tenha havido sintoma ou sinal enquanto o doente estava vivo. Muitas vezes, como no paciente 3 , a alteração da função esfincteriana só é notada quando o paciente tem o curso da doença artificialmente prolongado por respirador. Conclui-se destes estudos que estes núcleos também podem ser acometidos na DNM, mas que têm maior resistência à doença, levando à preservação de suas funções por tempo mais prolongado ${ }^{31}$.

Estabelece-se, na literatura, que a maioria dos pacientes com AMP sobrevive além de 5 anos ${ }^{1,7,21}$, uma sobrevivência maior que a encontrada nos pacientes com ELA (de 3 a 5 anos). O tempo médio de duração da doença neste estudo foi de 44 meses. Os pacientes que tiveram início dos sintomas acima dos 50 anos tiveram uma sobrevida ainda menor. Explicações para o fato de uma menor sobrevida dos nossos doentes em relação ao descrito na literatura podem se basear num menor acesso a cuidados respiratórios domiciliares ou mesmo pelo maior acometimento bulbar, o qual é um fator que sabidamente piora o prognóstico da doença, encurtando a sobrevida'. Por outro lado, Kristensen et al. ${ }^{4}$ encontraram sobrevida mais curta, 24 meses, mas não definiram qualquer fator predi- 
tor do prognóstico e da evolução do quadro. Contudo, a análise dos nossos casos permite inferir que a partir do envolvimento bulbar o curso da doença se acelera, como já observado em outro estudo ${ }^{5}$. A idade avançada quando do início da doença já foi citada também como fator de mau prognóstico ${ }^{32}$, mas há os que creditem isso à maior incidência de início bulbar dos sintomas em indivíduos com mais idade, o que ratifica que a inauguração bulbar da doença é o principal fator de pior prognóstico ${ }^{4}$. A localização inicial ou a progressão e quantidade de fasciculações também não foram decisivas para a forma de progressão da AMP, observação já feita por Müller ${ }^{1}$. Em todos os casos a causa de óbito foi falência da musculatura bulbar, com insuficiência respiratória, e esta é considerada a mais comum causa de morte entre os pacientes com $\mathrm{DNM}^{1,32}$. $\mathrm{O}$ paciente 3 não teve sua causa de óbito esclarecida, mas morte súbita e colapso circulatório têm sido descritos como causa de morte em pacientes com DNM dependentes de respirador ${ }^{33}$.

Considerando que os nossos pacientes apresentaram sinais isolados de envolvimento do NMI, no período compreendido entre o início das manifestações da doença até o óbito, acreditamos que realmente a AMP deva ser considerada uma situação isolada da ELA. Como não foi realizada necropsia em nenhum dos doentes, não há comprovação anatomopatológica de que o acometimento seja realmente exclusivo do NMI, exigindo do médico muitas vezes longo tempo de acompanhamento na espera da definição do diagnóstico.

\section{REFERÊNCIAS}

1. Müller R. Progressive motor neuron disease in adults: a clinical study with special reference to the course of the disease. Acta Psychiat Neurol 1952;27:137-156.

2. Swank RL, Putnam TJ. Amyotrophic lateral sclerosis and related conditions: a clinical analysis. Arch Neurol Psychiat 1943;49:151-177.

3. Gunnarsson LG, Bodin L, Söderfeldt B, Axelson O. A case-control of motor neuron disease: its relation to heritability, and occupational exposures, particularly to solvents. Bri J Ind Med 1992;49:791-798.

4. Kristensen O, Melgaard B. Motor neuron disease: prognosis and epidemiology. Acta Neurol Scand 1977;56:299-308.

5. Mortara P, Chiò A, Rosso MG, Leone M, Schiffer D. Motor neuron disease in the Province of Turin, Italy, 1966-1980: survival analysis in an unselected population. J Neurol Sci 1984;66:165-173.

6. Norris F, Shepherd R, Denys E, et al. Onset, natural history and outcome in idiopathic adult motor neuron disease. J Neurol Sci 1993;118:48-55.

7. Schiffer D, Brignolio F, Chió A, Leone M, Rosso MG. A study of prognostic factors in motor neuron disease. Adv Exp Med Biol 1987;209:255-262.

8. Brownell B, Oppenheimer DR, Hughes JT. The central nervous system in motor neuron disease. J Neurol Neurosurg Psychiatry 1970;30:338-357.
9. Thomas PK. Separating motor neuron diseases from pure motor neuropathies. Clinical clues and definitions. In Rowland LP (ed). Advances in neurology. Vol. 56: Amyotrophic lateral sclerosis and other motor neuron diseases. New York: Raven Press, 1991:381-384.

10. Rodrigues NR, Owen N, Talbot K, Ignatius J, Dubowitz V, Davies KE. Deletions in the survival motor neuron gene on $5 q 13$ in autosomal recessive spinal muscular atrophy. Hum Mol Genet 1995;4:631-634.

11. The Scottish Motor Neuron Disease Research Group. The Scottish motor neuron disease register: a prospective study of adult onset motor neuron disease in Scotland. Methodology, demography and clinical features of incident cases in 1989. J Neurol Neurosurg Psychiatry 1992;55:536-541.

12. Kendal HO, Kendal FP, Wadsworth GE. Muscle testing and function, $2^{\text {nd }}$ ed. Baltimore: Willians \& Willians, 1971

13. Haverkamp L, Appel V, Appel SH. Natural history of amyotrophic lateral sclerosis in a database population: validation of a scoring system and a model for survival prediction. Brain 1995;118:707-719.

14. Dietrich-Neto F, Callegaro D, Dias-Tosta E, et al. Amyotrophic lateral sclerosis in Brazil: 1998 national survey. Arq Neuropsiquiatr 2000;58:607-615.

15. Deapen DM, Henderson BE. A case-control study of amyotrophic lateral sclerosis. Am J Epidemiol 1986;123:790-799.

16. Felmus MT, Patten BM, Swanke L. Antecedent events in amyotrophic lateral sclerosis. Neurology 1976;26:167-172.

17. Armon C, Daube JR, Windebank AJ, Kurland LT. How frequently does classic amyotrophic lateral sclerosis develop in survivors of poliomyelitis? Neurology 1990;40:172-174.

18. Appel SH, Stockton-Appel V, Stewart SS, Kerman RH. Amyotrophic lateral sclerosis: associated clinical disorders and immunological evaluations. Arch Neurol 1986;43:234-238.

19. Rosen DR, Siddique T, Patterson D, et al. Mutations in $\mathrm{Cu} / \mathrm{Zn}$ superoxide dismutase gene are asociated with familial amyotrophic lateral sclerosis. Nature 1993;362:59-62.

20. Moulard B, Salachas F, Chassande B, et al. Association between centromeric deletions of the SMN gene and sporadic adult-onset lower disease. Ann Neurol 1998;43:640-644.

21. Leigh PN, Ray-Chaudhuri K. Motor neuron disease. J Neurol Neurosurg Psychiatry 1994;57:886-896.

22. Li T-M, Alberman E, Swash M. Clinical features and associations of 560 cases of motor neuron disease. J Neurol Neurosurg Psychiatry 1990;53:1043-1045.

23. Rowland LP, Shneider NA. Amyotrophic lateral sclerosis. N Engl J Med 2001;344:1688-1700.

24. Visser J, van den Berg-Vos RM, Franssen H, et al. Mimic syndromes in sporadic cases of progressive spinal muscular atrophy. Neurology 2002;58:1593-1596.

25. Younger DS, Rowland LP, Latov N, et al. Motor neuron disease and amyotrophic lateral sclerosis: relation of high CSF protein content to paraproteinemia and clinical syndromes. Neurology 1990;40:595-599.

26. Guiloff RJ, Mcgregor B, Thompson E, Blackwood W, Paul E. Motor neurone disease with elevated cerebrospinal fluid protein. J Neurol Neurosurg Psychiatry 1980;43:390-396.

27. Kelemen J, Hedlund W, Orlin JB, Berkman EM, Munsat TL. Plasmapheresis with imunossuppression in amyotrophic lateral sclerosis. Arch Neurol 1983;40:752-753.

28. Tan E, Lynn J, Amato AA, et al. Immunosuppressive treatment of motor neuron syndromes. Arch Neurol 1994;51:194-200.

29. Parhad IM, Clark AW, Barron KD, Staunton SB. Diaphragmatic paralysis in motor neuron disease. Neurology 1978;28:18-22.

30. Iwata M. Clinico-pathological studies of long survival ALS cases maintained by active life-support measures. Adv Exp Med Biol 1987;209:223-225.

31. Mannen T, Iwata M, Toyokura Y, Nagashima K. Preservation of a certain motoneuron group of the sacral cord in amyotrophic lateral sclerosis: its clinical significance. J Neurol Neurosurg Psychiatry 1977;40:464-469.

33. Eisen A, Schulzer M, Macneil M, Pant B, Mak E. Duration of amyotrophic lateral sclerosis is age dependent. Muscle Nerve 1993;16:27-32.

34. Shimizu T, Hayashi H, Kato S, Hayashi M, Tanabe H, Oda M. Circulatory collapse and sudden death in respirator-dependent amyotrophic lateral sclerosis. J Neurol Sci 1994;124:45-55. 